\title{
"Não fale com estranhos": solidariedade e comunicação entre identidade e alteridade ${ }^{1}$
}

\section{"Don't talk to strangers": solidarity and communication between identity and otherness}

\author{
Angela Cristina Salgueiro Marques \\ Doutora em Comunicação Social pela Universidade Federal de Minas Gerais (UFMG). Professora do Programa de Pós-Graduação \\ em Comunicação Social da UFMG. \\ <angelasalgueiro@gmail.com> \\ Luis Mauro Sá Martino \\ Professor do Programa de Pós-Graduação em Comunicação da Faculdade Cásper Líbero. Doutor em Ciências Sociais pela \\ Pontifícia Universidade Católica de São Paulo (PUC-SP). \\ $<$ Imsamartino@gmail.com>
}

\section{RESUMO}

Este trabalho delineia alguns aspectos da noção de "comunidade", a partir de uma perspectiva que entrecruza comunicação, moral, política e alteridade. $\mathrm{Na}$ medida em que as formas comunicacionais parecem estar diretamente ligadas com a dinâmica das sociabilidades, o trabalho avalia criticamente o argumento de que os vínculos comunitários são estabelecidos a partir de uma dicotomia entre as possibilidades de comunicação dos que estão "dentro" e o silenciamento dos que estão "fora". Argumentamos que a superação dessa divisão pode ser obtida no estabelecimento de relações comunicacionais menos assimétricas, pautadas na solidariedade e na amizade.

Palavras-chave: Comunidade. Alteridade. Política.

\begin{abstract}
This paper outlines some aspects of the notion of 'community' from a standing point that intermeshes communication, moral, politics and alterity. As communication seems to be closely linked to the dynamics of sociabilities, the paper critically discuss the argument that 'communities' may be characterized by its inside-outside dichotomy in communication: the condition of an 'insider' is given by its right to communicate to others, as the 'outsider' condition is marked by silence. This dichotomy, the paper goes further to argue, might be overcome by means of friendship and solidarity, which implies a less asymmetrical communication relationship.
\end{abstract}

Keywords: Community. Otherness. Politics.

\section{Introdução}

O parentesco etimológico inicial entre as noções de "comunicação" e "comunidade" permite algumas aproximações relativas ao entendimento do ato de "comunicar" dentro de um sentido no qual está implicado não apenas o sentido de um relacionamento com o outro, mas também a qualificação

1 A realização deste trabalho contou com o apoio do CNPq e da FAPEMIG. 
desse relacionamento dentro de um tipo específico de vínculo - o caráter "comunitário", em oposição a outros.

Entender a noção de "comunidade" em sua perspectiva do ato de "tornar comum" pode auxiliar a compreensão da comunicação como um tipo específico de relação social caracterizado por uma dimensão que vem se procurando entender como sendo uma aproximação estética e política com a alteridade.

Não há, evidentemente, pretensão de ineditismo nessa aproximação. Os trabalhos de Paiva (1999), Miani (2011), Macedo e Gonçalves (2014) ou Yamamoto (2014) vêm se desenvolvendo no sentido de pensar abordagens do conceito de "comunidade" para o estudo da Comunicação em sua interface com a Política e a Filosofia.

Além dos textos consagrados de Agamben (2012) ou Buber (2012), nota-se a tentativa de construção de interseções em vários aspectos. McLeod, Scheufele e Moy (1999), Mahrt (2008), Self (2010) e Holohan (2014) destacam a importância da interação conversacional no aspecto de configuração dos debates e das produções de decisões comunitárias sobre política, mas dentro de universos restritos. Os casos abordados por estes autores, vale destacar, se apoiam sobretudo em comunidades já existentes. A "comunidade", nesses trabalhos, é entendida dentro de sua oposição à "sociedade", perspectiva clássica na Sociologia - algo similar ao feito por Abellán e Mayugo (2009) ao tratar das relações de educação para a mídia em um grupo local.

A proposta aqui, em uma descendência oblíqua desses estudos, é trabalhar alguns aspectos da noção de "comunidade" que podem iluminar alguns elementos do conceito de "comunicação", entendido dentro de uma perspectiva relacional que pode envolver o midiático - no sentido usual da palavra como "meio de comunicação" impresso ou eletrônico - sem se reduzir a ele, podendo mesmo dele prescindir na eleição dos sentidos de contato e relação como pontos centrais da Comunicação.

O texto se posiciona, portanto, na perspectiva de autores interessados em compreender o comunicacional como uma dimensão relativa (mas não redutível) ao midiático, sublinhando o aspecto interacional e ético da relação comunicativa e buscando, ao mesmo tempo, qualificá-la diante da interação comunitária. Mais do que oferecer uma resposta, procura-se aqui delinear elementos que têm constituído essa interrogação na medida em que vem sendo trabalhada por vários autores (Wolton, 2011; Marcondes Filho, 2012; Ferrara, 2013; Martino; Marques, 2014; Marques; Martino, 2015).

A indagação que se poderia desenvolver na esteira de questionamentos realizados por Braga (2010), França (2006) ou Signates (2010) delineia-se ao 
refletirmos sobre quais são as formas de comunicação estabelecidas no interior de determinados regimes de sociabilidade e, em uma relação que não presume anterioridades lógicas ou cronológicas, em que medida esses regimes são igualmente estabelecidos por formas específicas de comunicação presentes no seu âmbito. Pensando a partir desses autores, busca-se evidenciar a contribuição que a Comunicação - como área, mas também como epistemologia específica - tem a oferecer para a compreensão de determinados fenômenos sociais.

Esta perspectiva tenta pensar em uma episteme comunicacional que se relaciona com a constituição de formas de sociabilidade distintas. A proposta, mais do que isso, é pensar a comunicação como uma das esferas iniciais de constituição de regimes de sociabilidade, nos quais as condições específicas de relações sociais acontecem a partir "da" e "com" a comunicação.

A constituição das sociabilidades tendo a comunicação como um de seus elementos distintivos talvez contribua para se pensar, no movimento tensional inverso, de que maneira tipos diferentes de relações comunicacionais são igualmente constitutivos de tipos de sociabilidade, pensando, nesse caso, 0 especificamente comunicacional como objeto de conhecimento e de estudos diante de outros fenômenos sociais.

A mirada rumo ao tipo de relação comunicacional que é estabelecida no âmbito de certos regimes de sociabilidade não pode fundar uma relação causal entre ambos, mas posicioná-los em uma articulação tensional complexa. A busca, aqui, é por aproximações e tensionamentos, não reduções.

\section{Os vínculos comunicacionais da comunidade}

A raiz comum dos conceitos de "comunidade" e "comunicação", bem como de outros termos relacionados, já foi objeto de análise por vários autores (Williams, 2001; Lima, 1983; 2001). Esses estudos retomam, sobretudo, a perspectiva da palavra communicare, do Latim, entendida como "tornar comum". Communis é uma tradução para o conceito grego de koinos, "aquilo que não é particular", em oposição ao oikos, o "particular" - que o Latim traduzirá como o domus, o espaço "particular" que se opõe ao publicus.

Note-se a variação: o oikos, que no grego se opunha ao koinos, parece ganhar uma ambiguidade no Latim na medida em que o domus se opõe ao mesmo tempo ao publicus e também ao communis. No primeiro sentido, a derivação está na orientação do politikós, aquilo que é referente à pólis, enquanto no segundo o termo se relaciona fundamentalmente ao koinos.

Essa ideia, se correta, permite identificar que a ideia do "comum" (koinos, communis) pode ser articulada com o "público" (publicus; politikós) e o "privado" 
(oikos; domus). A opção aqui é por entender o "comum" como algo "articulado com" o público e o privado, não "situado entre": a categoria do "comum" não se apresenta como locução intermediária entre outros termos que poderiam ser mais importantes ou específicos, mas como elemento primário de um tipo de relação.

A noção proposta por Agamben (2012), nesse aspecto, é o "qualquer": o "comum" se estabelece como um vínculo do "qualquer", elemento que, embora conserve sua propriedade - ele não é absolutamente indistinto na medida em que isso simplesmente implicaria, reductio ad absurdum, sua dissolução, mas ao mesmo tempo não se distingue por nenhuma característica específica que ressaltaria sua singularidade, transformando-o no "próprio": o "qualquer" se desenvolve dentro de uma perspectiva que implica, ao mesmo tempo, o universal e o singular, em um vínculo intermediário de estabelecimento de uma potência de relação. O estado do "qualquer" como o intermediário entre a potência absoluta do universal e o ato finito do singular encontra-se também no caráter intermediário daquilo que é "comum": é de todos sem pertencer sem ser "próprio" - a ninguém.

A noção de algo "comum", neste caso, parece implicar uma relação comunicacional que se estabelece como vinculação específica de potências, na possibilidade do gesto comunicativo vinculador que transforma a singularidade não no universal - afinal, a comunicação se dá com alguém -, mas no ato da relação com um outro. A perspectiva do qualquer, no sentido que se pode inferir de Agamben, parece pressupor a noção de comunidade como uma forma de relação humana na qual o vínculo é também regulado por um tipo de comunicação que pressupõe o endereçamento a um outro com qualidades que não lhe são singulares, mas que caracterizam ou tipificam a própria relação.

É importante notar, nesse aspecto, a proposição que se pode trazer a partir do pensamento do autor de uma diferença entre o aspecto da "comunidade" e das formas midiáticas de comunicação que, ao transformarem o social em espetáculo - e aqui Agamben dialoga diretamente com Debord - tem algumas de suas qualidades de agenciamento dissolvidas na potencialidade fantasmática dos meios produtores desse espetáculo.

Esposito (2007) escava, dentro da noção de "comunicação", um elemento anterior ao "tornar comum" como ato de "compartilhar", questionando o que, de fato, é compartilhado para o estabelecimento de um elemento "comum". Sua resposta aponta para a constituição de um vínculo baseado na perspectiva do múnus, emprestada à Antropologia para designar o elemento comum 
agregador de pessoas em torno de uma reciprocidade pautada em qualidades e obrigações de cada membro para com todos os outros.

A noção de múnus refere-se, nesse sentido, ao elemento que garante o vínculo comunitário: é a reciprocidade que forma o vínculo entre pessoas, tornando-as parte de uma comunidade. Esgarçando a perspectiva etimológica, a comunidade é o vínculo daqueles que possuem um determinado múnus e, por conta disso, estão ligados dentro de uma teia de obrigações mútuas das quais não se pode fugir sem deixar de lado o próprio sentido de uma "comunidade": o "estranho", nesse aspecto, não é apenas o "de fora", o outsider, mas também aqueles que, dentro da comunidade, são desprovidos ou destituídos desse múnus - o "imune", a immunitas destacada por Esposito (2007) como característica de uma modernidade na qual os regimes de vínculos comunitários são continuamente desafiados pelo individualismo imunizado contra o outro, na ausência de compartilhamento de um múnus em uma perspectiva de "imunidade" em relação a uma alteridade.

A comunicação, neste aspecto, está relacionada à possibilidade de compartilhar o múnus com outras pessoas, estabelecendo-se como o elemento a partir do qual se instauram as relações sociais em sua visibilidade: as possibilidades de falar - "não fale com estranhos" - se relaciona diretamente com a chance de se saber qual é a potência do múnus que se compartilha.

Ao mesmo tempo, a comunicação dentro de uma comunidade, pensada em termos desse compartilhamento, reveste-se imediatamente de uma qualidade ritual em alguns casos, na medida em que a palavra se torna instrumento de definição/transmissão/compartilhamento do múnus existente entre a comunidade, a ser entendido e/ou desfrutado apenas por aqueles que também compartilham disso, em outras palavras, aqueles que pertencem à extensão potencial do múnus. Os outros, a alteridade, torna-se imune, o que em muitos casos parece implicar em uma imediata exclusão de qualquer vínculo em sua caracterização como o "outro".

Os sujeitos manejam as regras de interpretação - fundadas pelos significados compartilhados do sensus communis - e se servem delas para instaurar um contexto de reconhecimento mútuo que visa ao entendimento recíproco. Contudo, o sensus communis está sujeito a reavaliações a mudanças que se processam ao mesmo tempo em que as práticas sociais se modificam e se transformam mediante a ação criativa dos sujeitos sociais empenhados em suas relações com os outros, seus parceiros.

Uma comunidade do gosto organiza-se através do senso comum, ou do sensus communis, koinos aesthesis, que, como afirma Parret (1997, p. 197), "é o 
senso de uma comunidade que (...) não é nem argumentativa, nem consensual: ela é afetiva." O consenso não precisa ser buscado de forma afoita, porque os significados já estão dados (mas não são estanques). É deles que os sujeitos partem para interpretar. Não é o formular julgamentos que realmente importa e sim o uso de pré-julgamentos nas práticas conversacionais.

É através da dinâmica comunicativa que as sociedades se reinventam e garantem sua permanência. A comunicação traz sempre à tona o senso comum criado pela comunidade, possibilitando que os sentidos sejam reapropriados pela experiência de modo que ao mundo não seja devolvida a forma comum que instaura a relação, mas uma forma estranha, nova (em sua forma de aparecer) e legítima, pronta para encorpar o conjunto do conhecimento partilhado.

\section{O silêncio dos estranhos na comunidade}

A comunicação reflete um desejo de estar com o outro, de aceitar o desafio que o outro nos lança por meio de sua singularidade, de sua diferença. O encontro com o outro na comunidade se expressa sempre de forma agonística, na qual um indivíduo incita e interpela o outro por meio da dúvida, do estranhamento, sendo que ambos se relacionam agonisticamente por meio da reciprocidade e da interdependência (Buber, 2009; 2012).

Mas, uma vez que nos colocamos frente aos outros, desejamos que eles nos reconheçam, nos respeitem e não que nos desprezem ou desrespeitem, transformando diferenças em fronteiras intransponíveis. Os sujeitos que se inserem nas práticas comunicativas do cotidiano desejam ter sua singularidade reconhecida, suas habilidades devidamente respeitadas e seu modo de viver incluído na "gramática" dos modos de vida aprovados e valorizados pela sociedade objetivada em cada uma das pessoas com as quais se interage.

A individualidade dos sujeitos, suas experiências próprias, suas crenças e ações ganham sentido quando expostas ao outro, quando questionadas ou reforçadas pelo apoio solidário vindo do mundo que é do outro. $O$ reconhecimento do mundo do outro deve, além de laços afetivos, éticos e políticos, envolver uma comunicação ligada às práticas compartilhadas dos indivíduos (Honneth, 1995).

Tais práticas se formam e se estabelecem na comunidade. Segundo Lash (1995, p. 188), essas práticas são regidas por regras institucionalizadas, mas "envolvem um investimento imediato de sentimentos sobre os instrumentos utilizados - incluindo os signos - e sobre outros seres humanos com quem as práticas são compartilhadas". 
O engajamento dos sujeitos sociais na produção de um mundo comum se dá tanto por meio da comunicação como por meio de um agir conjunto. Entretanto, no mundo comum deve haver o reconhecimento do mundo subjetivo do outro, posto que sua autoestima e suas ligações afetivas no cotidiano comunitário estão em jogo. Eu me apresento diante do outro e espero dele compreensão, uma certa abertura ao diálogo, pois é através dessa relação que as narrativas identitárias se moldam e se expressam, relações se estreitam ou são cortadas (Lagerkvist, 2014).

O que devemos observar, então, é que a maneira pela qual nos posicionamos frente ao outro, que oferecemos nossa individualidade ao perscrutamento alheio, obedece menos a regras explícitas, institucionalizadas, do que a conveniências implícitas, acordos tácitos de comportamento subentendidos e tidos como certos e "bons". Tais acordos de conveniência não se separam do que é mundano, do rotineiro, dos significados compartilhados cotidianamente no mundo da vida. Eles fazem parte do processo de socialização humana. E, se num primeiro momento as regras de conveniência são aprendidas, posteriormente elas se tornam inconscientes, aflorando em nossas interrelações despercebidamente. O que é "bom" para uma comunidade está presente nesse código de conveniências e valores configurados por um "nós" na prática cotidiana.

Uma vez que a comunidade é constituída por uma pluralidade de indivíduos, que se mantêm conectados a relações e grupos ainda mais plurais, podemos perceber a importância adquirida pela dimensão do reconhecimento social. Grupos e indivíduos que sofrem injustiças simbólicas (seja no campo de sua representação, interpretação ou significação) anseiam não só por novas formas de representação, mas pelo seu reconhecimento e pela valorização de suas contribuições à coletividade (Martín-Barbero, 1995, p. 45).

É preciso lembrar aqui que a busca por reconhecimento não se restringe à afirmação da diferença, o que pode isolar os sujeitos e aprofundar distâncias, além de criar núcleos de violência e agressividade aos "estranhos".

No entanto, a comunidade resiste em incorporar ou incluir aqueles indivíduos que não se adeqüam às regras implícitas de conveniência que regem a gramática dos modos de vida sociais amplamente aceitos como moralmente válidos. Aqueles que insistem em manter um estilo de vida tido como inconveniente ou impróprio são excluídos de âmbitos legais, estéticos, políticos e afetivos da comunidade. Assim, os "estranhos" expõem as fissuras e falhas que compõem o comum, descortinando os danos promovidos por uma lógica consensual segundo a qual todos estariam incluídos e seriam iguais. 
A comunicação atualiza os códigos que norteiam as práticas dos indivíduos em comunidade. É por meio dela que posições são revistas, que argumentos são considerados e re-considerados, enfim, que a comunidade avança em suas formas de representar, interpretar e significar o mundo tomado em sua complexidade. Os significados compartilhados, arraigados na tradição e na cultura - bem como nos códigos e gestos comportamentais - devem ser renovados, re-criados por uma forma de sociabilidade que não desconsidere o "diferente", que não tema o risco de investir na novidade, na reabilitação de um "estar-juntos" movido pelo reconhecimento da pluralidade que caracteriza a política e todos os âmbitos sociais.

O que se coloca então, é a busca de uma sociabilidade revigorada, que constitui a comunidade por meio de dissensos, consensos e de ambivalências, pautada por uma moral renovada. A sociabilidade deve ser captada como uma forma fluida, criativa, aberta, uma vez que se serve de modos de vida já comumente reconhecidos e constantemente à espera de re-criação.

O que é, neste aspecto, o estranho?

Seria possível caracterizar o "estranho" como o "outro". Certamente o "estranho" está nas proximidades do "outro": no entanto, é necessária uma distinção entre ambos: o"outro", o alter, é uma alteridade que, se não é alcançável em sua totalidade, também não é inatingível: o alter se funda na relação com o ipso: uma condição da alteridade é a ipseidade. Há uma proximidade paradoxal com o outro que não se reduz ao estabelecimento de uma fronteira: o outro pode ser atingido, pode me atingir, pode constituir um "nós". O "estranho", no entanto, parece pertencer a uma categoria que implica um deslocamento mais profundo em relação à alteridade". Mais do que o "alter", o estranho é o alien.

O "estranho", o "estrangeiro", pode ser inicialmente ligado a um deslocamento espacial: o "estranho" relaciona-se com o alien, do Latim, "outro", o "estrangeiro". O "estranho", no sentido do "estrangeiro", é o xenos da Grécia antiga: aquele que estava fora de seu lugar e que, por conseguinte, em um lugar que não é seu.

O alien se refere a uma exterioridade: o alien está situado no "fora" de um lugar específico, a noção de lugar, nesse caso, assume uma condição metafórica na definição que vai situar esse alien em relação a fronteiras - físicas ou simbólicas - previamente definidas. Em geral, vale acrescentar, definidas por quem está "dentro": de certa maneira, as relações do alien com aqueles que pertencem a um determinado grupo podem se equivaler à perspectiva do ipso e do alter: o alien é também um alter, na medida em que aquele que está fora, o que vem do espaço do fora e se constitui quase sempre como um estranho 
em relação ao que está dentro: a condição de ser colocado "fora", no sentido de um "deslocamento" para com algo que existe se revela em derivados como o "alienado", aquele que, em termos bastante pejorativos - citado aqui, portanto, como exemplo negativo - se refere ao que está "fora de si" em termos da própria consciência.

O estranho surge, assim, como o que está para além dos limites da comunidade e não pode ser tomado de modo algum como pertencente a ela; quando a interseção no espaço físico é inevitável, surge a figura do alien como elemento constituinte de uma ordem instaurada que regula - e é regulada pela possibilidade de comunicação: no sentido mais comum, a ideia do "não fale com estranhos" sugere, na recomendação familiar, a distinção relativa àqueles que pertencem a uma determinada comunidade de pessoas com quem se pode estabelecer o vínculo de comunicação.

A alteridade se converte em silêncio exatamente por sua condição de estranho. Silêncio simbólico, mais do que propriamente acústico: o outro fala, mas sua fala não reverbera no espaço social porquanto não tem legitimidade para ser ouvida e, se ouvida, considerada digna de ser escutada (Koskinen e Lindström, 2013). A fala do estranho não é entendida como comunicação, mas como ruído. Ele não alcança, assim, o status de interlocutor.

Sob esse aspecto, o estado do "fora" caracteriza o "estranho": sua qualidade de alien, nesse sentido, ganha independência da questão territorial presente em sua origem: o estranho está fora aonde quer que esteja. O sentido de deslocamento se transfere, na acepção moderna, para o espaço social e mesmo psicológico no qual reside a qualidade essencializada - não essencial, evidentemente - do estranho: seu lugar é algures, sua presença, mais do que a outrem, se aprofunda na diferença que não é tornada familiar.

\section{A solidariedade e o vínculo comunicacional}

Não podemos desconsiderar os apontamentos de Bauman (1999) referentes à produção de estranhos numa ordem que se queria impor através de métodos científicos e técnicos. Os estranhos ("loucos", "deficientes", "iletrados", "punks", "baderneiros", "imigrantes”, etc) não estão mais reclusos, estão nas ruas, querem ser vistos e anseiam ser reconhecidos como sujeitos capazes de decidir por si mesmos como querem viver suas próprias vidas. Contudo, é preciso lembrar aqui que essa decisão não é tomada solitariamente, nem fora dos contextos, constrangimentos e contingências que cercam os indivíduos. Formas de opressão, assimetrias e desigualdades materiais e simbólicas interferem de modo diferenciado sobre as decisões e preferências dos indivíduos. Assim, 
muitas demandas de reconhecimento não dependem apenas de transformações individuais, mas sobretudo de mudanças institucionais e morais.

Se as ações dos sujeitos comportam uma reflexão sobre o que pretendem e a natureza do que é conquistado, as instituições têm buscado uma maior interação com o mundo da vida. A reflexividade é um fazer para além das práticas, um fazer que exige a re-invenção, o dobrar-se sobre si mesmo de forma criativa, que volte ao plano social como um suplemento, um "algo mais" instaurador de novos ciclos e novos fazeres (Lash, 1995).

O "estar-juntos" não depende só de práticas compartilhadas ditadas pela tradição ou mesmo por instituições, mas depende também dos laços de empatia, solidariedade e amizade formados entre os indivíduos que compõem uma dada comunidade. Nesse sentido, podemos afirmar que os significados compartilhados originam uma comunidade, sim. Contudo, somente o sentimento de solidariedade alimenta a coesão dos laços sociais, bem como possibilita o gesto de religar o indivíduo ao todo relacional e múltiplo que é a rede comunitária (Morin, 1997, p. 22).

A sociedade precisa de algo mais que práticas e significados partilhados para manter-se unida. E a força que mantém a comunidade atada não vem, portanto, da imposição, mas sim da solidariedade que se instaura entre seus membros. Solidariedade esta mantida, por exemplo, pela "ética da amizade" (Ortega, 2000), a qual consiste na busca de lugares e modos de produção de subjetividades a partir de vínculos que não se esgotam na família e no casamento, por exemplo. Tal ética considera a pluralidade dos indivíduos e não tenta homogeneizá-los por meio da imposição de normas de vida ou imagens dominantes, unificadoras, que dificultam a criação e experimentação de vínculos de sociabilidade e afeto.

Segundo Ortega (2000) não se pode confundir a amizade com fraternidade universal, uma vez que esta encontra-se associada historicamente a práticas de exclusão, desumanização e perseguição: em nome da igualdade e da fraternidade cristãs, por exemplo, formas violentas de intolerância e aniquilamento das diferenças. Ele nos endereça a pergunta:

É possível imaginar uma nova política da amizade além da reciprocidade, da proximidade, das metáforas familiares e divisões binárias, e da identificação do outro com o mesmo? Tratar-se-ia de uma amizade e de uma democracia generosa com uma diferença multilingual, multirracial, multicultural, bem como multissexual." [...] Ela encontra-se além do direito, das leis, da família e das instâncias 
sociais, representando uma alternativa as formas de relacionamento prescritas e institucionalizadas (Ortega, 2000, p. 79 e 89).

Inspirado pelas filosofias políticas de Blanchot, Derrida, Deleuze e JeanLuc Nancy, Ortega tenta considerar a amizade como forma política e estética, tanto de existência como de sociabilidade, no desenho político da comunidade. Para ele, a amizade vincula-se permanentemente ao novo, ao contingente, uma vez que os encontros que temos com os outros carregam a potência do inusitado, instigando alternativas às formas tradicionais de relacionamentos dentro das comunidades. Esta forma renovada de sociabilidade estaria apta a incorporar os estranhos em seu processo de luta por reconhecimento simbólico.

Tal sociabilidade só pode ser alcançada por indivíduos que compartilham um mundo comum e nele se comunicam, desde que esses indivíduos façam avançar a tradição por meio de um investimento, um engajamento na ação de criar e recriar formas de interação social voltadas para o mundo tais como a amizade, a cortesia, a solidariedade, a hospitalidade, o respeito mútuo. Pois, todas essas formas de conviver apontam para a preservação da pluralidade de relações, significados, práticas e indivíduos dispostos na rede multiforme tecida pela e na comunidade.

A renovação da política da amizade, fundada na solidariedade, pode ser, segundo Ortega (2000, p. 13), a melhor forma de manter estreitos os laços comunitários. Para ele, a amizade pode se transformar num meio de reinvenção das relações políticas, de modo que "ante uma sociedade que limita e prescreve as formas de relacionamento, a amizade seria a experimentação de novas formas de sociabilidade."

A amizade, ao marcar a diferença e a distância entre os seres, sua assimetria e divisão, seria uma alternativa possível para a abertura e acolhimento/ hospitalidade aos "diferentes", pois exige novas imagens e metáforas para os sentimentos, para o autoentendimento e também para o ser-em-comunidade. Amizades são assimétricas, no sentido de que as diferenças entre os amigos provocam, incitam, deslocam, produzem um agonismo que ressalta as distâncias intransponíveis.

A pluralidade se configura num estímulo para a reflexão sobre a singularidade das identidades de cada indivíduo. Deste modo, o "estranho" nos impõe um desafio: o de sacudir formas fixas de sociabilidade, principalmente aquelas que os consideram como inimigos, como geradores da desordem e 
do medo. O risco que este desafio coloca é que saibamos desenvolver uma percepção sensível para as diferenças de opinião e de gostos.

A solidariedade que acompanha o vínculo da amizade, ao recusar a dissolução do outro no mesmo, prepararia o caminho para que formas de vida até então desprezadas criem seu próprio modo de ser na/em comunidade. Vemos, com isso, que a ética da amizade não define um único estilo de vida como o correto e "bom", mas sim valoriza a pluralidade de estilos adotados por indivíduos e grupos igualmente plurais em sua multiplicidade.

Ortega argumenta que a política da amizade possibilita a experimentação de um mundo comum que una e separe os indivíduos ao mesmo tempo, mantendo sempre a distância entre eles, condição da pluralidade. Isso pede um investimento, um engajamento na ação de criar e recriar formas de interação social tais como a cortesia, a solidariedade, a hospitalidade, o respeito. O que esse autor propõe não é a fusão ou inclusão do diferente na comunidade que aí já está, mas um exercício criativo de produzir novos significados, espaços e imagens de contato com o outro, sem prescrever um único modo de existência como correto.

Reconhecer o mundo do outro implica tomar contato com novos valores, significados e modos de conviver agonisticamente com o Outro, em uma provocação permanente. O estranho não é necessariamente o inimigo: tudo depende de que forma de sociabilidade está sendo investida pelos sujeitos em interação. "Relações agonísticas são relações livres que apontam para o desafio e para a incitação recíproca e não para a submissão ao outro" (Ortega, 2000, p. 89). Cabe à comunicação sustentar uma intersubjetividade que privilegie formas de ser com o outro baseadas no respeito à singularidade, à inventividade e à pluralidade de sujeitos agrupados em comunidades de sentidos, os quais originam os mundos compartilhados e também as fronteiras, desterritorializações e cisões.

A sociabilidade é condição primeira para o reconhecimento. O estarcom-o-outro requer mútuo respeito, mútua simpatia ligados a sentimentos que impulsionem o indivíduo a prosseguir seu projeto de vida de acordo com os preceitos que ele julga serem melhores para sua autorrealização. É através de nossas relações intersubjetivas que nos fazemos, que vemos e revemos nossas escolhas, posturas, valores e posições.

É interpelando os outros e sendo por eles interpelados que os sujeitos se reconhecem como membros de uma comunidade e reconhecem os outros como seus pares de interação (Honneth, 1995). A trama que resulta de tais interações é feita de fios narrativos que entrelaçam as histórias biográficas 
subjetivas, a cultura, os significados compartilhados coletivamente e, é claro, as formas simbólicas providas pelos meios de comunicação e nos ambientes digitais.

É sobre estes últimos que recaem amplas expectativas ligadas ao reconhecimento, pois suas mensagens são amplamente difundidas e incorporadas à fala cotidiana, fornecendo assim, material não só para a construção da identidade, mas também para alimentar os conflitos simbólicos. A luta por reconhecimento, além de ser um processo de aprendizagem social é, no contexto mediático, um potencializador de demandas por inclusão de identidades desvalorizadas e tidas como "desviadas" de um padrão normativo amplamente aceito.

O reconhecimento mútuo, então, depende da propagação e compartilhamento das expectativas de comportamento normativo, sendo que estas se apresentam intimamente ligadas às conveniências seguidas nas práticas do convívio humano. Para ser reconhecido, o sujeito deve se servir das regras que o tornam cúmplice de determinados modos de conviver de sua sociedade.

É claro que agir de acordo com as regras de conveniência social não implica em suprimir as diferenças e singularidades individuais. Se a luta por reconhecimento tem início na busca por um "código comum" negado, sua motivação maior se sustenta na diferença, naquilo que foi causa de desrespeito. Por isso, o reconhecimento é um aprendizado com raízes na intersubjetividade e nas práticas do mundo da vida - na comunicação.

\section{A comunidade política de partilha}

Segundo Pierre Ouellet (2002), a comunidade não deve ser entendida como algo fundado sobre a ideia de propriedade ou pertencimento, obedecendo a relações de exclusão e de inclusão, que isolariam os indivíduos. Para ele, as comunidades não se constituem em torno de um denominador comum, mas de um vazio, de um intervalo, de uma lacuna de coexistência que pode ser transposta, mas nunca preenchida ou eliminada. Essa tentativa de transpor o intervalo existente entre diferentes pessoas, percepções de um "comum" e afinidades se faz por meio da experiência sensível que temos de nós mesmos e dos outros.

Além disso, essa é uma experiência política e moral configurada por ações comunicativas, conflituais e estéticas que alimentam, respectivamente, negociações em torno da contextualização de momentos interlocutivos, táticas criativas e performáticas quem rompem com as regras da argumentação 
transparente e igualitária, e performances que visam evidenciar a construção sensível, temporal e situacional do ato enunciativo e interlocutivo.

A comunidade de Ouellet não está dada de antemão: ela é resultado da criação e recriação de cenas polêmicas de enunciação performática dos sujeitos que, ao lutarem para ter seus discursos considerados e para constituíremse como interlocutores que desejam dizer e se fazer ouvir, estabelecem uma comunidade política que possui o mundo comum como pano de fundo préexistente para as interações e como fruto do processo de coexistência.

O trabalho da criação política do "nós" requer a modelagem de um comum. O "comum" é, ao mesmo tempo, o que une e o que separa, o consenso e o dissenso, a rendição e a resistência. Ele pode ser descrito como a "dimensão intervalar na qual nos remetemos uns aos outros e a nós mesmos", configurandose por meio da "instituição de intervalos que ligam sujeitos e realidades, sem englobá-los nem integrá-los" (Tassin, 1992, p. 33).

Também Silva (2011) aponta o comum como resultado de um intervalo, como um espaço vazio no qual damos forma ao "entre nós" e à reciprocidade, um espaço de escuta e de acolhimento de outras temporalidades, sem, contudo, estar isento das distinções e das distâncias. Para ele, "comum é tudo aquilo que nos oferece os recursos de uma livre busca de uma identificação que não está dada, que não está constituída. Aquilo que o comum afirma é justamente esse espaço da liberdade, esse vazio que é a possibilidade da comunidade" (Silva, 2011, p. 20).

O comum de uma comunidade é menos aquilo que é "próprio" de um grupo ou de uma cultura e mais o lugar de exposição e aparecimento dos intervalos e das brechas que permitem uma ação comum através da linguagem, de modo a promover não formas de "ser em comum" (que muitas vezes apagam ou incorporam diferenças, suprimindo singularidades), mas formas de "aparecer em comum". Eis aqui uma questão central: o "comum" de uma comunidade diz do "aparecer" dos sujeitos na esfera de visibilidade pública como interlocutores dignos de respeito e estima.

Assim, o surgimento de um mundo comum é um acontecimento que registra os traços de visibilidade dos indivíduos, conectando-os e separando-os, assegurando-Ihes o pertencimento a um mesmo espaço social e multiplicando seus intervalos. Por isso, é possível afirmar que "o operador essencial da instituição simbólica do mundo comum é a visibilidade sobre uma cena de aparição" (Quéré, 1995, p. 97).

A formação de um mundo comum está intimamente ligada à construção pragmática do espaço público, compreendido por Tassin como 
"jogo de separações vinculantes e de vínculos separadores" (1992, p. 33). O espaço público, enquanto mundo comum, abrange, em primeiro lugar, uma pluralidade de comunidades que só se transformam em "comunidade de uma pluralidade", porque o espaço público é intervalar, isto é, ele conecta sujeitos e universos particulares não para dar origem a um être-en-commun, mas a um vivre ensemble marcado por interrupções, fraturas e intervalos de subjetivação. Esta última, implica a descoberta de uma capacidade de enunciação que não podia ser identificada em um campo previamente existente da experiência. A produção de um novo campo de experiência requer, portanto, uma concepção de comunidade que ofereça brechas para o questionamento das "identidades e dos lugares definidos em um espaço determinado em um mundo já dado; identidades e lugares definidos à exemplo de outros espaços; e identidades e lugares que não têm espaço" (Rancière, 1995, p. 186). Viver juntos e em meio a fraturas torna-se mais desafiante que "ser em comum", uma vez que viver com o outro requer sua consideração, a apreensão sensível de seu mundo e de suas marcas sem necessariamente incorporá-las ao próprio universo.

É o espaço existente "entre" os sujeitos que, por meio do diálogo, se manifesta no espaço público. Não se trata, portanto, da atualização de uma essência comum ou de uma "essência do comum". O espaço público, lócus da comunidade política, é sempre da ordem do dissenso, da política e da reconfiguração.

Uma comunidade política que se estrutura através de relações que são estabelecidas em meio a uma constante divisão e compartilhamento entre os seus membros, na criação de um "comum" é chamada por Rancière de "comunidade de partilha". Segundo ele, a comunidade de partilha abrange o "pertencimento dos sujeitos a um mesmo mundo que só pode adquirir sentido por meio da polêmica, e a união que só pode se realizar por meio do combate" (2004, p. 92). Ele a caracteriza como uma "comunidade de intervalos", em que "o ser em comum" é definido pelos vínculos que ligam os sujeitos sem tirá-los do registro da separação. A comunidade de partilha (ou intervalar) é o âmbito em que se reconfigura o "comum de uma comunidade", isto é, em que se questiona "as coisas que uma comunidade considera que deveriam ser observadas, e os sujeitos adequados que deveriam observá-las, para julgá-las e decidir acerca delas" (Rancière, 2004, p. 12).

A comunidade política de partilha parte de uma definição da igualdade que possibilita a afirmação de cada indivíduo como alguém que compartilha um mundo comum e, ao mesmo tempo, preserva os intervalos entre uma multitude de experiências individuais. Tal definição pode dar a ver um tipo de 
comunidade em que todos deveriam tratar seus parceiros de interação como iguais, com base no fato de que todos são potenciais interlocutores, capazes de falar e dignos de serem ouvidos e considerados. Mas essa igualdade não é dada a priori. Ela só é alcançada por meio de "testes" concretos de verificação que desafiem o entendimento (o já dado) de que existem princípios de igualdade que asseguram, de antemão, o acesso de todos os indivíduos à linguagem, à visibilidadee à interlocução. Por isso, para Rancière, a comunidadeéinconsistente e intervalar: ela se mantém suspensa devido ao ato constante de sua verificação por homens que trabalham pela criação contínua da igualdade (2004, p. 162).

Esse tipo de comunidade "acontece" como processo de construção e constante redefinição do lugar ocupado pelo sujeito político, um lugar que deve ser compreendido como um intervalo ou um hiato que se forma entre classificações externas, autoentendimentos e situações culturais que configuram as interações entre o "eu" e o "outro". Para Rancière, formas de agir e de ser do sujeito que tendem mais ao desentendimento permitem instaurar uma comunidade política de partilha na qual a igualdade é o exercício constante de regular a proximidade e a distância entre seus membros. Seria preciso, então "aprender a recriar a cada instante o próximo e o distante que definem os intervalos da comunidade" (2004, p. 199).

O vínculo e os modos de ação dos membros que integram uma comunidade dessa natureza privilegiam não uma reafirmação das diferenças entre grupos, mas uma reconfiguração da distribuição de ordens do visível, do audível e do comunicável, deslocando os limites e questionado uma ordem sensível excludente.

Formas de comunidade política não têm como objetivo fazer coincidir semelhantes e dessemelhantes, mas revelar que a partilha de um mundo comum é feita, ao mesmo tempo, da tentativa de estabelecer ligações entre universos fraturados e da constante resistência à permanência desses vínculos.

A comunidade política de partilha contrapõe dois modos de "viver juntos": um deles distribui corpos e vozes segundo os modos de ser, fazer e dizer que convêm a cada um. $O$ outro suspende a harmonia do senso comum revelando a contingência e a fragilidade de uma pressuposição igualitária entre todos os sujeitos de palavra.

De acordo com Rancière (2004), a comunidade de partilha opõe um espaço consensual a um espaço polêmico: ela faz aparecer sujeitos e falas que até então não eram contados ou considerados, ela traz à experiência sensível vozes, corpos e testemunhos que até então não eram vistos como pertencentes ao regime igualitário. A comunidade consensual, ao não registrar essas vozes, corpos e testemunhos como interlocutores, estabelece um dano 
que deve ser discutido em um espaço polêmico. "Esse procedimento cria uma comunidade de partilha no duplo sentido do termo: um espaço que pressupõe o compartilhamento da mesma razão, mas também um espaço cuja unidade só existe por meio da divisão" (Rancière, 2004, p. 166).

A comunidade de partilha dá corpo a uma tentativa de introdução daqueles que não faziam parte do registro sensível do comum na comunidade consensual de pressuposição igualitária. Ela é a brecha que permite testar o princípio da igualdade da comunidade ideal de linguagem ao trazer para o espaço público aqueles que não eram considerados como capazes de integrar a ordem do discurso e da visibilidade. Ao mesmo tempo, ela dá nome aos anônimos, dá a ver sua singularidade e, de alguma forma, faz com que essa singularidade, ao conservar sua distância, nos pareça familiar.

\section{Considerações finais}

Segundo Rancière (2012, p. 65), a política da estética "consiste na elaboração do mundo sensível do anônimo, dos modos do isso e do eu, do qual emergem os mundos próprios do nós político". Isso implica construir outras formas de senso comum (dados partilhados por todos), outras comunidades de palavras, formas e significados. Outros enunciados que possam promover um dizer e uma voz capazes de iniciar o vai e vem da interpelação, da resposta e da responsabilidade pelo comum e sua elaboração.

Além disso, se a incerteza é uma nova maneira de produzir os sujeitos que têm suas identidades multipartidas, fragmentadas, palimpsesticas - como fazer da vida uma experiência estética forte escapando dos determinismos da Indústria Cultural que sujeita os indivíduos a aceitar modelos prontos, miméticos - e não poiéticos - de construir as práticas rotineiras? Uma saída é, talvez, a valorização dos hábitos e práticas compartilhadas situadas na comunidade. A partir desse universo comunal, os sujeitos podem modificar sentidos estrategicamente preparados pelo dispositivo homogeneizante da Indústria Cultural e do consumo.

Os tipos sociais produzidos pela modernidade e que agora estão soltos, no meio da sociedade que se quer ordeira, que deseja que os estranhos fiquem escondidos e entocados nos subúrbios, nos enclaves distantes da cidade, dos shoppings, das empresas e vitrines badaladas.

Uma das maiores dificuldades da sociedade contemporânea é saber lidar com os estranhos que produz. A ambigüidade é inerente aos contextos em que diferença, alteridade e sociabilidade são requisitados para que os indivíduos estabeleçam contatos que visem o mútuo entendimento. $E$ isso não exclui as diferenças, ao contrário, elas são o fator principal da intersubjetividade. O desafio 
não está no plano da ordem, mas de uma convivência que, de acordo com Honneth (1995) se dê através de lutas por reconhecimento e alcance um ponto de vista moral, iluminador de ações de justiça que descortinem assimetrias e evidenciem dispositivos reprodutores de opressões e violências.

Lutas que se desenrolam tanto na esfera íntima quanto na esfera pública e são articuladas em torno que normas morais e valores que necessitam ser revistos e tornados mais justos. Se, por um lado, a mobilização de grupos tratados injustamente é rápida, por outro, a mudança de valores da sociedade é lenta e atada a estigmas de várias qualidades.

A ética da amizade proposta por Ortega nos lembra que o gesto político por excelência consiste em acolher o outro em nosso olhar, em nossa palavra, em nosso mundo, estabelecendo passagens que são pontilhadas de espaços relacionais, nos quais o tempo se torna mais lento e mais generoso com os interlocutores, que podem, enfim, criar, inventar cenas de interpelação nas quais há a emergência de um estado de disponibilidade, de escuta, de doação. A hospitalidade para com o estrangeiro nos humaniza enquanto humaniza o estranho para quem inauguramos a possibilidade de ser amparado, escutado, considerado. Uma experiência política da alteridade requer de nós abertura incondicional ao encontro, ao choque mesmo resultante de "sofrer" uma experiência, ou seja, deixar-se afetar pela diferença e permitir que o outro nos modifique, modifique nossa forma de ver, de ser e de existir no mundo e com os outros. Essa não é uma transformação que se realiza sem dor, sem desconsiderar os riscos de acolher o estranho, sem uma dose de violência e uma exigência de desidentificação com identidades fixas, homogeneizantes, consensuais e redutoras que impedem o florescimento da pluralidade e da experimentação que permite à vida momentos de silêncio, opacidade, deslocamento e pausa.

O espaço cotidiano, frequentemente marcado pelo antagonismo (o ódio ao estranho e o desejo de seu apagamento) e não pelo agonismo, raramente oferece um momento de convivência que aceite o estranho em um acolhimento não baseado em regras institucionalizadas, e sim feito por meio de uma interlocução solidária, de uma comunicação reflexiva e criativa, que buscam, por meio de valores e afetos comuns, fazer avançar tanto as narrativas identitárias individuais e coletivas, quanto as experimentações e potências dos encontros entre singularidades e mundos possíveis.

\section{REFERÊNCIAS}

ABELLÁN, G.; MAYUGO, C. La dimensión comunitaria de la educación en comunicación. Comunicar, v. XVI, n. 31, p. 129-136, 2008. 
AGAMBEN, Giorgio. A comunidade que vem. Belo Horizonte: Autêntica, 2012.

BAUMAN, Zygmunt. Modernidade e ambivalência. Rio de Janeiro: Jorge Zahar, 1999.

BRAGA, José Luiz. Nem rara, nem ausente - tentativa. Matrizes. v. 4, n. 1, p. 65-81, dez. 2010.

BUBER, Martin. Do diálogo e do dialógico. São Paulo: Perspectiva, 2009.

Sobre comunidade. São Paulo: Perspectiva, 2012.

ESPOSITO, Roberto. Communitas. Buenos Aires: Amorrortu, 2007.

FERRARA, Lucrécia D’Aléssio. A epistemologia de uma comunicação indecisa. In: XXII Compós, 2013, Salvador. Anais do XXII Encontro Anual da Associação Nacional dos Programas de Pós-Graduação em Comunicação. Salvador: UFBA, p. 1-17, 2013.

FRANÇA, Vera. Sujeitos da comunicação, sujeitos em comunicação. In: GUIMARÃES, C.; FRANÇA, V. R. V. Na mídia, na rua: narrativas do cotidiano. Belo Horizonte: Autêntica, 2006.

HOLOHAN, S. What is a Cohesive Community Anyway?: The Role of Mainstream Media in Narratives of (Dis)Integration. Middle East Journal of Culture and Communication, v. 7, n. 1, p. 27-45, 2014.

http://dx.doi.org/10.1163/18739865-00701009

HONNETH, Axel. Integrity and disrespect: principles of a conception of morality based on a theory of recognition. In: WHIGHT, C.W. (org.). The fragmented world of social - essays in social and political philosophy. New York: State University of New York Press, p. 247-260, 1995.

KOSKINEN, C. A. L.; LINDSTRÖM, U. A. Listening to the Otherness of the Other: Envisioning Listening Based on a Hermeneutical Reading of Lévinas. The International Journal of Listening, v. 27, n. 3, p. 146-156, set. 2013.

http://dx.doi.org/10.1080/10904018.2013.813259.

LAGERKVIST, A. A Quest for Communitas Rethinking Mediated Memory Existentially. Nordicom Review, v. 35, special issue, p. 205-218, 2014.

LASH, Scott. A reflexividade e seus duplos: estrutura, estética, comunidade. In: BECK, Ulrich.; GIDDENS, Anthony.; LASH, Scott. Modernização Reflexiva. São Paulo: Ed. UNESP, 1995.

LIMA, Venício. Mídia e Política. São Paulo: Perseu Abramo, 2001. Repensando as teorias da comunicação. In: MELO, J. M. Teoria e pesquisa em 
comunicação. São Paulo: Intercom/Cortez, 1983.

MACEDO, M. E.; GONÇALVES, L. M. A. Notas sobre os conceitos de comunidade, comunicação comunitária e dialogai. Comunicação \& Educação, São Paulo, v. 19, n. 1, p. 39-53, jun. 2014.

http://dx.doi.org/10.11606/issn.2316-9125.v19i1p39-49.

MAHRT, M. Conversations about local media and their role in community integration. Communications, v. 33, n. 2, p. 233-246, jan. 2008.

http://dx.doi.org/10.1515/COMMUN.2008.013.

MARCONDES FILHO, Ciro. A Comunicação no sentido estrito e o Metáporo. In: XXII Compós, 2012, Juiz de Fora. Anais do XXI Encontro Anual da Associação Nacional dos Programas de Pós-Graduação em Comunicação. Juiz de Fora: UFJF, p. 1-17, jun. 2012.

MARQUES, A. C. S.; MARTINO, L. M. S. A comunicação, o comum e a alteridade: para uma epistemologia da experiência estética. Logos, Rio de Janeiro, v. 22, n. 2, p. 31-44, 2015.

MARTINO, L. M. S.; MARQUES, A. C. S. Aproximações e ambivalências epistemológicas da pesquisa que se constitui entre a comunicação e o comunicar. Lumina, Juiz de Fora, v. 8, n. 1, p. 1-19, 2014.

MARTÍN-BARBERO, Jésus. Dos meios às mediações: comunicação, cultura e hegemonia. Rio: UFRJ, 1995.

McLEOD, J. M.; SCHEUFELE, D. A.; MOY, P. Community, Communication, and Participation: the role of mass media and interpersonal discussion in local political participation. Political Communication, v. 16, n. 3, p. 315-336, 1999.

http://dx.doi.org/10.1080/105846099198659.

MIANI, R. A. Os pressupostos teóricos da comunicação comunitária e sua condição de alternativa política ao monopólio midiático. Intexto, Porto Alegre, v. 2, n. 25, p. 221-233, dez. 2011.

MORIN, Edgar. Complexidade e ética da solidariedade. In: CASTRO, G. (org.). Ensaio de complexidade. Porto Alegre: Sulina, p.15-24, 1997.

ORTEGA, Francisco. Para uma política da amizade: Arendt, Derrida, Foucault. Rio de Janeiro: Relume Dumará, 2000.

OUELLET, Pierre. (org.). Politique de la parole. Singularité et communauté. Montréal: Trait d'union, collection “Le soi et l'autre", p. 7-20, 2002.

PAIVA, Raquel. O espírito comum. Rio de Janeiro: Mauad, 1999. 
PARRET, Herman. A estética da Comunicação: além da pragmática. São Paulo: Ed. UNICAMP, 1997.

PIERUCCI, Antônio Flávio. Ciladas da Diferença. São Paulo: Ed. 34, 1999.

QUÉRÉ, Louis. L'espace public comme forme et comme événement. In: JOSEPH, Isaac (org.). Prendre Place: espace public et culture dramatique. Pontigny-Cerisy : Éditions Recherches, p. 93-110, 1995.

RANCIÈRE, Jacques. Aux bords du politique. Paris: Gallimard, 2004.

La Mésentente- politique et philosophie. Paris: Galilée, 1995.

O espectador emancipado. São Paulo: Martins Fontes, 2012.

SELF, C. C. Hegel, Habermas, and Community: The Public in the New Media Era. International Journal of Strategic Communication, v. 4, n. 2, p. 78-92, 2010.

http://dx.doi.org/10.1080/15531181003704651.

SILVA, Rodrigo. Apresentação (elegia do comum). In: SILVA, Rodrigo; NAZARÉ, Leonor (org.). A república por vir. Arte, Política e Pensamento para o século XXI. Lisboa: Fundação Calouste Gulbenkian, p. 11-37, 2011.

TASSIN, Etienne. Espace commun ou espace public? L'antagonisme de la communauté et de la publicité, Hermès, n. 10, p. 23-37, 1992.

WILLIAMS, Raymond. Keywords. Londres: Fontana, 2001.

WOLTON, Dominique. Informar não é comunicar. Porto Alegre: Sulina, 2011.

YAMAMOTO, Eduardo. O conceito de comunidade na Comunicação. Revista Famecos, Porto Alegre, v. 2, n. 21, p. 34-46, 2014.

Recebido em: 16/8/2016

Aceito em: 28/9/2016

Endereço dos autores:

Angela Cristina Salgueiro Marques <angelasalqueiro@gmail.com>

Programa de Pós-Graduação em Comunicação Social da UFMG

Avenida Antônio Carlos, 6.627 - Campus Pampulha - sala 4234

31270-901 - Belo Horizonte (MG) - Brasil

Luis Mauro Sá Martino <lmsamartino@gmail.com>

Programa de Pós-Graduação em Comunicação da Faculdade Cásper Líbero

Avenida Paulista, 900 - Bela Vista

01310-940 - São Paulo (SP) - Brasil 